\title{
Analysis of Gold Jewellery Artifacts
}

\author{
CHARACTERIZATION OF ANCIENT GOLD SOLDERS BY PIXE
}

\author{
G. Demortier \\ L.A.R.N., Facultés Universitaires de Namur, B-5000 Namur, Belgium
}

\begin{abstract}
For many years it has been widely assumed that in artifacts from antiquity in which parts were joined by soldering or brazing, such solders or brazes were cadmium-free. Recent analyses using particle induced $X$ - orgamma-ray emission techniques have cast doubt upon this bypothesis.
\end{abstract}

When analyzing jewellery items the ideal method of analysis should be quantitative, accurate, reliable, topographical, but above all non-destructive and suitable to give the chemical composition of different parts of a piece of jewellery without any sampling, even at microscopic level.

Particle Induced X-ray Emission (PIXE) and Particle Induced Gamma-ray Emission (PIGE, sometimes called PIGME), are two techniques used specially with the objects under investigation at atmospheric pressure, which exhibit most of these qualities. When used simultaneously, these two techniques are capable of solving most of the problems of interference often present in prompt physical methods of analysis.

The physical principles of elemental analysis of solids using prompt signals induced during the irradiation of the objects with projectiles heavier than electrons are described followed by $\dot{a}$ discussion of the application of these principles for topographical analyses of gold jewellery items. Special attention is focussed on the determination of the chemical composition of natrow regions situated at solders evident or expected from the construction of the item.

A new approach to ancient gold brazing with regard to the presence of cadmium is discussed. It takes into account recent observations obtained from experiments performed to attempt to rediscover a possible ancient technology for the fabrication of brazing alloys involving only rudimentary means, that is the use of a mixture of gold (or electrum) and natural cadmium mineral, the colour of which is close to that of gold, in a charcoal furnace.

\section{Prompt Analytical Techniques}

Let us briefly consider from an analytical point of view the physical principles of prompt nuclear and atomic interactions induced by the bombardment of an object with particles the energy of which lies in the $\mathrm{MeV}$ range.

When protons of energy in the $\mathrm{MeV}$ range interact with the atomic components of a sample, four types of reactions useful for analytical purposes may be produced:

(1) Elastic scattering of the incident particles

(2) Nuclear reactions giving rise to emission of charged particles

(3) Coulomb excitation or resonant absorption immediately followed by $\gamma$-ray emission

(4) Ionization of electrons from their inner shells followed by hard $\mathrm{X}$-ray emission.

All the signals from these reactions are produced in a very short time $\left(10^{-9}\right.$ to $\left.10^{-20} \mathrm{~s}\right)$ and they may be called prompt reactions by comparison with delayed emission of particles and/or radiations obtained in activation analysis: the emission of photons ( $\mathrm{X}$ and/or $\gamma$-ray) and charged particles induced by low energy charged particle bombardment stops when the incident beam is stopped.

Rutherford elastic scattering (mainly in the reverse direction) has been successfully used in material analysis for quantitative determination of heavy elements in matrices of low atomic weight. At a given reverse angle, the energy of the scattered particles depends only on the ratio of the mass of this incident projectile to that of the nucleus collided with: the greater is the mass of the target nucleus the greater is also the energy of the scattered particle. This kind of interaction does not change the nature of the collided nuclei.

The second type of reaction (emission of charged particles other than the incident one) may give analytical information when the incident particles have an energy which is sufficient to cross the Coulomb barrier of the target nucleus. The analytical interest of this type of reaction is thus restricted to the analysis of elements of low atomic weight, and mainly for lithium, boron, carbon and nitrogen for which the limit of detection lies in the $10 \mu \mathrm{g} / \mathrm{g}$ region. Thiskind of interaction gives rise to a transmutation of the collided nucleus.

Both these abovementioned reactions are then of little interest for the purposes of the analysis of elements in heavy matrices such as those contained in gold artifacts.

The Coulomb repulsion between the incident particle and a positive atomic nucleus of the material under analysis does not allow the proton to penetrate in heavy nuclei to eject particles. Fortunately, when the emission of such massive particles is forbidden, the quantum mechanical behaviour of nuclear interactions allows $\gamma$-ray emission, even when the Coulomb barrier does not allow the incident particle to collide with the nucleus. The parameters governing this kind of reaction have been extensively studied during the beginning of the second half of this century and identification of nearly all the chemical elements by energy dispersive photon detectors is now possible (1). The elements used in gold jewellery include gold, copper, silver, zinc, cadmium and iron (encountered either as a component or as an impurity) and, in the case of modern sophisticated materials, nickel, germanium, rhodium, palladium and platinum. When the incident proton energy is increased from $\leq 3$ to up to $10 \mathrm{MeV}$, transmutation of elements may then be induced and residual activity of irradiated samples expected (2). This phenomenon is used for analytical purposes but the delayed activity of the sample is often undesirable. 
The limits of detection by prompt $\gamma$-ray analysis are better than 1 per cent for all of the above mentioned elements and for a time of bombardment of less than $\mathrm{th}$ and when no major interference is suspected.

This sensitivity is often sufficient to determine the concentrations of the most abundant elements of the alloy but the shape of the $\boldsymbol{\gamma}$-ray spectrum with an important 'background' from the long tail Compton scattering does not allow sufficient accuracy to be reached due to statistical uncertainty on the determination of the areas of each characteristic peak. Figure 1 gives an illustration of such a spectrum recorded when a modern soldering alloy ( 75 gold $/ 3$ silver $/ 8$ copper $/ 2$ zinc $/ 12$ cadmium per cent is irradiated in a beam of $3 \mathrm{MeV}$ protons). These reactions leading to the emission of $\gamma$-rays may be used for the characterization of the most abundant components of all materials but they are especially useful for the analysis of lithium, boron, beryllium, fluorine, sodium, magnesium and aluminium in all kinds of matrices: the limit of detection for all these light elements is in the range of $10 \mu \mathrm{g} / \mathrm{g}$ in materials whose matrices are composed of elements of high atomic mass.

The use of the fourth prompt phenomenon(X-ray production) solves the problem of lack of accuracy for the analysis of heavy and medium mass elements. When each proton loses its energy in the thick sample, it removes electrons from their specific shells. After a hole is created in a $\mathrm{K}$ or Latomic shell, electronic rearrangements occur with emission of $\mathrm{K} \mathrm{X}$-rays (and also Auger electrons particularly for elements of low atomic mass). For the medium mass elements, it is possible to observe two $X$-ray lines $(K \alpha$ and $K \beta)$ in a good $\mathrm{Si}(\mathrm{Li})$ detector; for heavier elements, four lines $\left(\mathrm{K} \alpha_{1}, \mathrm{~K} \alpha_{2}\right.$, $K \beta_{1}$ and $K \beta_{2}$ ) may be detected. For heavy elements $L$ shell

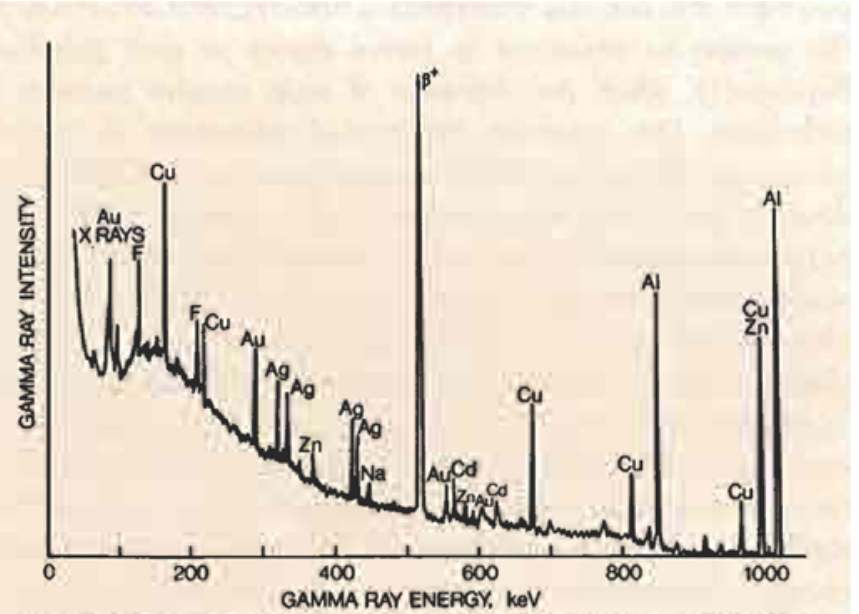

Fig. 1 Gamma-ray spectrum obtained during the irradiation with $3 \mathrm{MeV}$ protons of a modern gold braze containing gold, silver, copper, cadmium and zinc ionizations give rise to 5 isolated X-ray peaks: $\mathrm{L}, \mathrm{L} \alpha, \mathrm{L} \eta, \mathrm{L} \beta, \mathrm{L} \gamma$ which are more intense than $K$ lines and thus more valuable for accurate analysis. The ratios of the intensities of these lines are well established and do not vary with the chemical environment of the elements. The author has written in depth on the treatment of PIXE data elsewhere $(3,4)$. In Table I are gathered the most useful

Table I

Characteristic X-rays Useful for Analysis of Metals in Gold Jewellery

\begin{tabular}{|c|c|c|c|c|c|}
\hline \multirow[b]{2}{*}{ Element } & \multicolumn{2}{|c|}{ X-ray } & \multicolumn{3}{|c|}{ Interferences } \\
\hline & line & $\begin{array}{l}\text { energy, } \\
\text { keV }\end{array}$ & element & $\begin{array}{l}\text { ain } \\
\text { energy, } \\
\text { keV }\end{array}$ & secondary \\
\hline $\mathrm{Fe}$ & $\begin{array}{l}K \alpha \\
K \beta\end{array}$ & $\begin{array}{l}6.40 \\
7.05\end{array}$ & $\begin{array}{l}\text { Mn } \\
\text { Co }\end{array}$ & $\begin{array}{l}6.49 \\
6.93\end{array}$ & Dy, Sm \\
\hline $\mathrm{Ni}$ & $\begin{array}{l}K \alpha \\
K \beta\end{array}$ & $\begin{array}{l}7.47 \\
8.30\end{array}$ & & & $\begin{array}{l}\text { Dy, Eu } \\
\text { W, Tm }\end{array}$ \\
\hline $\mathrm{Cu}$ & $\begin{array}{l}K \alpha \\
K \beta\end{array}$ & $\begin{array}{l}8.05 \\
8.90\end{array}$ & & & $\begin{array}{l}\mathrm{Er}, \mathrm{Ta}, \mathrm{Tb} \\
\mathrm{Os}, \mathrm{Lu}, \mathrm{Hg}\end{array}$ \\
\hline $\mathrm{Zn}$ & $\begin{array}{l}K \alpha \\
K \beta\end{array}$ & $\begin{array}{l}8.64 \\
9.65\end{array}$ & $\begin{array}{l}\mathrm{Au} \\
\mathrm{Au}\end{array}$ & $\begin{array}{l}8.50 \\
9.70\end{array}$ & $\begin{array}{l}\mathrm{Re}, \mathrm{Yb} \\
\mathrm{Ta}, \mathrm{W}\end{array}$ \\
\hline $\mathrm{Ge}$ & $\begin{array}{l}K \alpha \\
K \beta\end{array}$ & $\begin{array}{r}9.85 \\
11.10\end{array}$ & $\begin{array}{l}\mathrm{Hg} \\
\mathrm{Pt}\end{array}$ & $\begin{array}{r}9.98 \\
11.10\end{array}$ & $\begin{array}{l}\text { W } \\
\mathrm{Po}, \mathrm{Pb}\end{array}$ \\
\hline Pd & $\begin{array}{l}\mathrm{K} \alpha \\
\mathrm{K} \beta_{1} \\
\mathrm{~K} \beta_{2}\end{array}$ & $\begin{array}{l}21.10 \\
23.80 \\
24.30\end{array}$ & $\begin{array}{l}\text { In } \\
\text { In }\end{array}$ & $\begin{array}{l}24.00 \\
24.20\end{array}$ & TC \\
\hline $\mathrm{Ag}$ & $\begin{array}{l}\mathrm{K} \alpha \\
\mathrm{K} \beta_{1} \\
\mathrm{~K} \beta_{2}\end{array}$ & $\begin{array}{l}22.15 \\
24.94 \\
25.45\end{array}$ & $\begin{array}{l}\text { Ru } \\
\text { Sn } \\
\text { Sn }\end{array}$ & $\begin{array}{l}22.07 \\
25.05 \\
25.27\end{array}$ & \\
\hline Cd & $\begin{array}{l}\mathrm{K} \alpha \\
\mathrm{K} \beta_{1} \\
\mathrm{~K} \beta_{2}\end{array}$ & $\begin{array}{l}23.15 \\
26.10 \\
26.64\end{array}$ & $\begin{array}{l}\mathrm{Rb} \\
\mathrm{Sb} \\
\mathrm{Sb}\end{array}$ & $\begin{array}{l}23.16 \\
26.10 \\
26.40\end{array}$ & \\
\hline $\mathrm{Pt}$ & $\begin{array}{l}L \ell \\
L \alpha \\
L \eta \\
L \beta \\
L \gamma\end{array}$ & $\begin{array}{r}8.27 \\
9.40 \\
9.97 \\
11.10 \\
12.95\end{array}$ & $\begin{array}{l}\mathrm{Cu} \\
\mathrm{Zn} \\
\mathrm{Ge} \\
\mathrm{Ge}\end{array}$ & $\begin{array}{r}8.05 \\
9.65 \\
9.85 \\
11.10\end{array}$ & $\begin{array}{l}\text { Ga } \\
\text { Se } \\
\mathrm{Se}, \mathrm{Br}\end{array}$ \\
\hline $\mathrm{Au}$ & $\begin{array}{l}L \ell \\
L \alpha \\
L \eta \\
L \beta \\
L \gamma\end{array}$ & $\begin{array}{r}8.50 \\
9.70 \\
10.30 \\
11.50 \\
\\
13.38\end{array}$ & $\begin{array}{l}\mathrm{Zn} \\
\mathrm{Zn} 9.65 \\
T 1\end{array}$ & $\begin{array}{l}8.64 \\
\text { Ge } 9.85 \\
10.27\end{array}$ & $\begin{array}{l}\mathrm{Se}, \mathrm{As}, \mathrm{Pb}, \\
\mathrm{Hg}, \mathrm{Mg} \\
\mathrm{Rb}\end{array}$ \\
\hline
\end{tabular}

Gold Bull., 1984, 17, (1) 


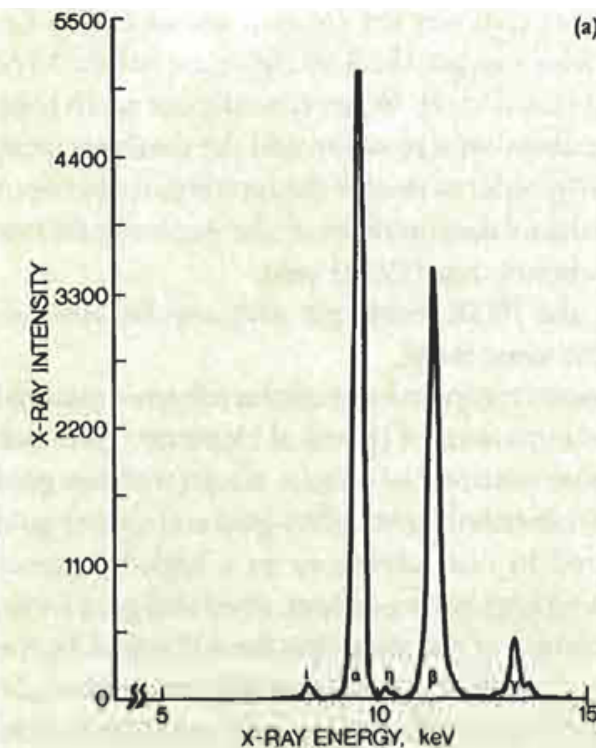

Fig. 2(a) X-ray spectrum obtained during the irradiation of a pure gold sainple

(b) Enlargement of the spectrum shown in Fig. 2(a) in the vertical scale. Note the five characteristic X-ray lines and the broadening of the X-ray lines at the bottom of $L \alpha$ and $L \beta$

(c) X-ray spectrum obtained during the irradiation of a cadmiumcontaining solder. The spectrum is recorded using a foil of zinc between the sample and the detector, giving rise to zinc lines by fluorescence. The horizontal scale has been reduced by a factor of two in order to display the $\mathrm{X}$-ray spectrum up to $30 \mathrm{keV}$

characteristics of the $\mathrm{X}$-ray lines of elements used in gold jewellery.

For each of the four abovementioned analytical techniques, the amount of material needed for a complete analysis is very small. Practically, the limitation comes from the handling of the sample. With a $3 \mathrm{MeV}$ proton beam of $1 \mathrm{~mm}$ in diameter, the useful part of the analyzed sample is less than $5 \times 10^{-3} \mathrm{~mm}^{3}$ or $100 \mu \mathrm{g}$ of a gold matrix. When the size of the proton beam is reduced to a surface diameter of 2 to $10 \mu \mathrm{m}$ by using strong focussing quadropoles the amount of material required for analysis is then reduced to $2 \mathrm{ng}$.

Taking advantage of the large cross-section for the production of significant X-ray signals, the complete compositional analysis of gold artifacts for nearly all the elements whose concentration is greater than 0.1 per cent is possible in less than 10 min of irradiation, and an equivalent time for the treatment of the data with a minicomputer. Figure 2 illustrates X-ray spectra recorded during the irradiation of pieces of ancient jewellery which will be discussed below. PIXE and PIGE are techniques for surface analysis: X-rays and $\gamma$-rays are induced in the first 3 to $10 \mu \mathrm{m}$ beneath the irradiated surface. Nevertheless the results from surface analysis may be extrapolated to give the composition of the bulk material if no surface corrosion is suspected. Thus gold artifacts are more amenable to this treatment than those of bronze or brass.
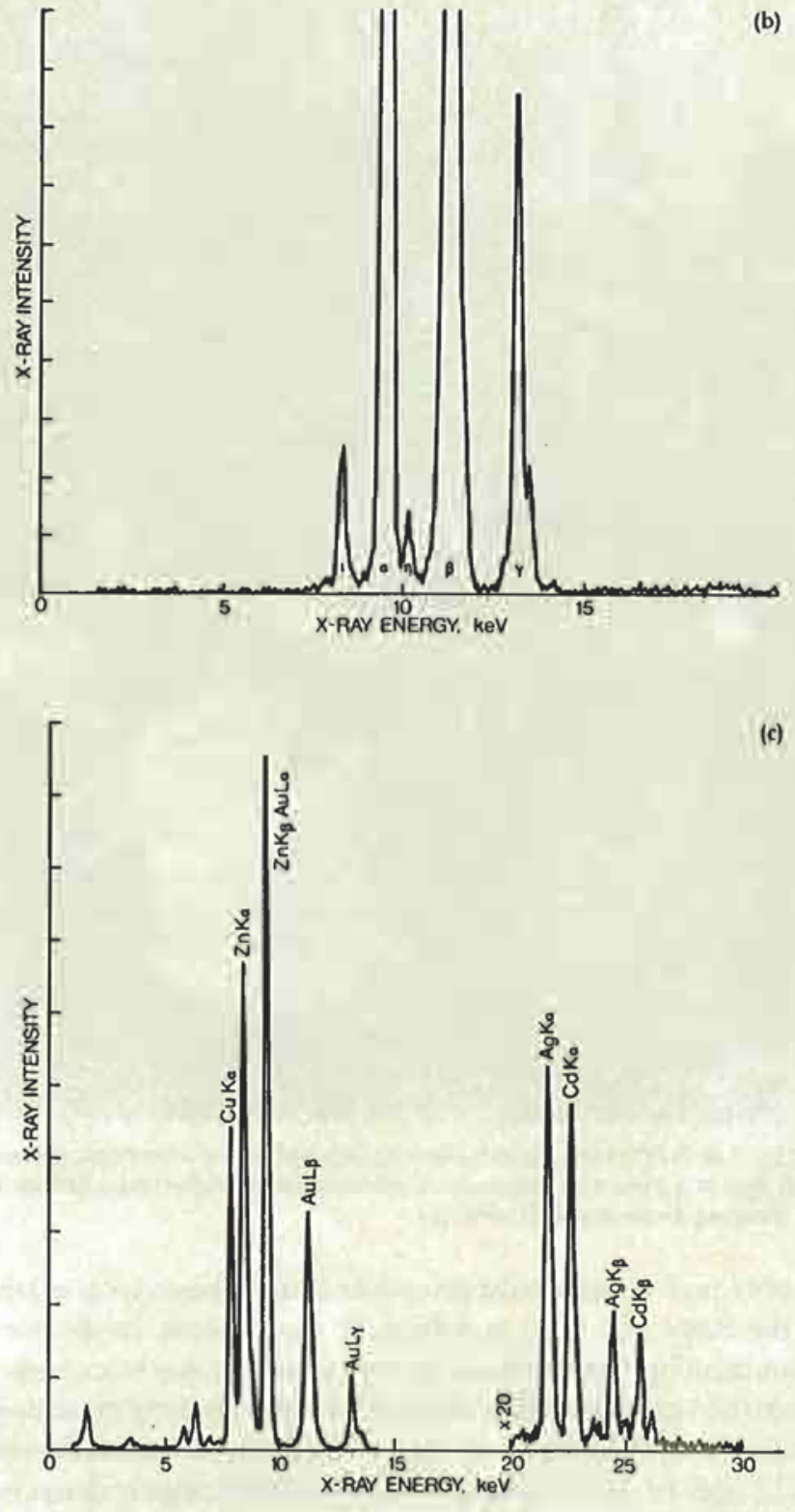

\section{Experimental Arrangement for PIXE Analysis}

As indicated earlier the ideal technique for analysis of artifacts must be rapid and strictly non-destructive and must offer good topographical resolution in order to be able to treat with equal success different characteristic regions of the artifact. The PIXE technique appears to satisfy these requirements.

Figure 3 illustrates the apparatus used for PIXE analysis. When the samples are irradiated out of the evacuated pipe of a particle accelerator beam spots of reduced area, at the site of the impact, may 


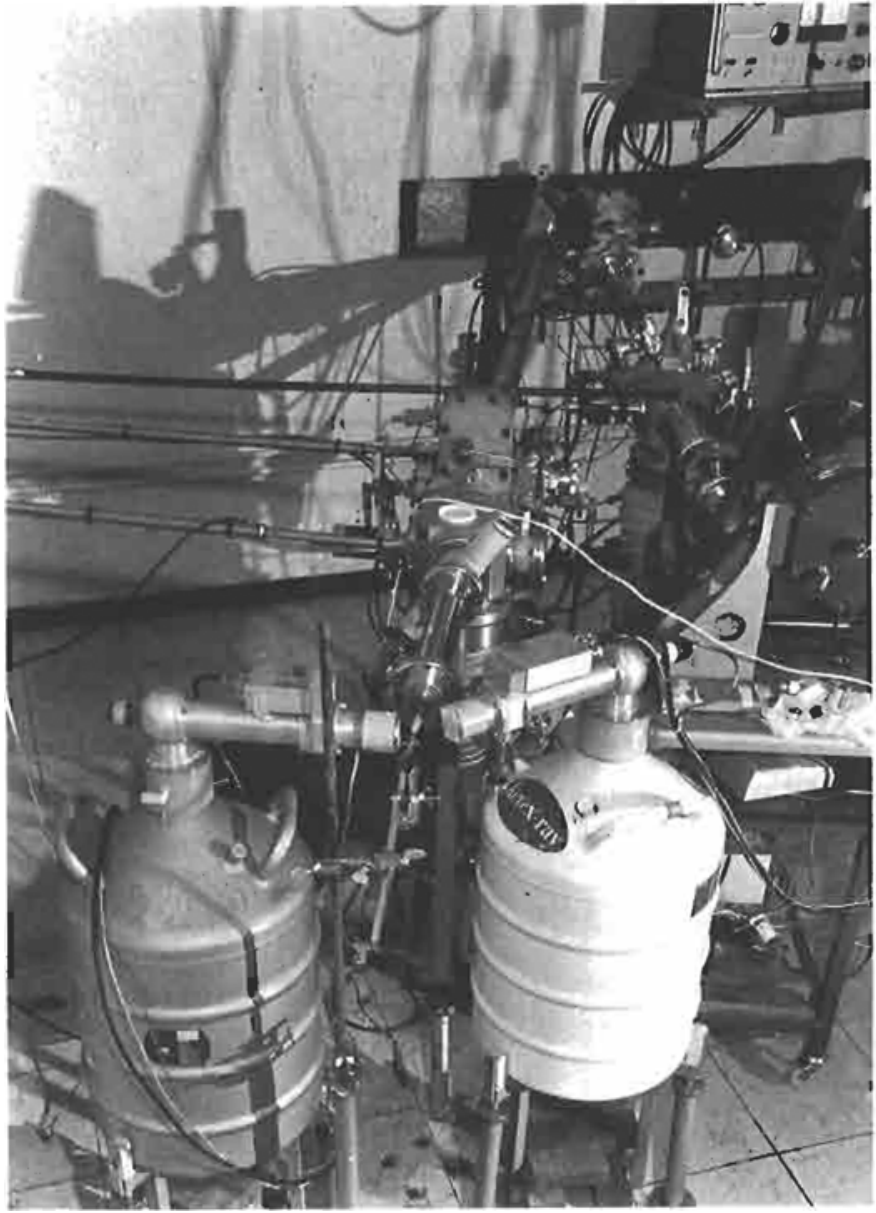

Fig. 3 A view of the PIXE apparatusshowing bombardment at atmospheric pressure of an artifact, a cross, with protons extracted from the accelerator and collection of the resulting $\mathrm{X}$-rays in a $\mathrm{Si}(\mathrm{Li})$ detector

be obtained: we refer to the procedure of using beam spots of area in the range of $1 \mathrm{~mm}^{2}$ as milliprobe experiments. In the nonvacuum milliprobe arrangement, the incident proton beam crosses a thin (12.5 $\mu \mathrm{m}$ thick) foil of aluminium before reaching the sample situated at a distance of $1 \mathrm{~cm}$ in air. Aluminium is used as the exit foil because its characteristic $\mathrm{X}$-rays are out of the range of detection of the $\mathrm{Si}(\mathrm{Li})$ assembly. When the diameter of the exit collimator supporting the foil is reduced to $0.5 \mathrm{~mm}$, the diameter of the proton beam is about $700 \mu \mathrm{m}$ at the target position.

The X-ray analysis is performed using a zinc foil (10 to $30 \mu \mathrm{m}$ thick) inserted between the target and the detector. Zinc is a selective absorber for Au L X-rays which allows us to reduce the total mean count rate by reducing mainly the contribution of the surabundant information from gold $\mathrm{X}$-rays, thus enhancing the sensitivity of detection of characteristic $\mathrm{K} \mathrm{X}$-rays from silver and cadmium. Unfortunately, zinc KX-rays produced by fluorescence in this foil also appear in the spectra and therefore zinc contained in the sample cannot be simultaneously analyzed. However, this element is expected to be (if present) in very low concentrations and its $\mathrm{K} \alpha$ $(8.631 \mathrm{keV})$ line interferes with gold $\mathrm{L} \ell(8.493 \mathrm{keV})$ and its $\mathrm{K} \beta(9.572$ $\mathrm{keV}$ ) with the gold $\mathrm{L} \alpha$ (see Table I). When zinc content needs to be determined, the zinc absorber is removed and the total spectrum is computer analyzed in order to resolve the interference between these lines. Bearing in mind this interference, the sensitivity for zinc determination is not better than 0.2 per cent.

For zinc analysis, the PIGE technique may also be used, its sensitivity being in the same range.

A set of alloys of known composition is used as reference material for quantitative determinations of chemical elements: gold-rich alloys ( 75 per cent) from commercial origins, alloys (with low gold content) from private collection origins, silver-gold and copper-gold binary alloys prepared in our laboratory in a high-frequency induction furnace using high purity copper, silver and gold wires. The nominal composition of the alloys has been checked by the PIGE technique using the pure elements as reference materials. Comparison of measured and certified values are in good agreement (4). The LARN proton microprobe with the sample mounted on a X-Y manipulation frame in the vacuum may also be used to scan the samples (mechanically as well as electrostatically). The vacuum chamber has been designed so as to be large enough to allow scanning on samples the largest dimension of which may be up to $30 \mathrm{~cm}$. In these microprobe experiments the beam spot is a rectangle of $5 \times 10 \mu \mathrm{m}$. That resolution is far from the best attainable spatial resolution $(-3 \mu \mathrm{m})$ but issufficient for the purpose of the present analyses.

In both experimental arrangements (milliprobe and microprobe) the full $\mathrm{X}$-ray spectra are recorded on floppy disks and are processed by computer in order to substract the actual background and to resolve peaks from neighbouring elements. No beam monitor is used during the experiments. It is assumed that the test material contains only gold, silver, copper, zinc and cadmium. Other elements sometimes present at trace level (for example chromium and iron) are of no importance for the purpose of the present study. If their concentration should affect the actual analysis obtained, their characteristic X-rays are well resolved and their presence can be taken into account. Calibration curves obtained from reference materials are checked by calculation using physical data on cross-sections, stopping powers and mass attenuation coefficients of X-rays. Ka lines are used for the analysis of copper, silver and cadmium, $L \beta$ for the analysis of Au. The statistical errors on the measured values are always less than 1 per cent for gold, less than 5 per cent (relative) for copper, silver and cadmium, if they are present at concentration higher than 3 per cent but always better than 10 per cent in all less favourable cases.

\section{The Soldering of Gold}

The brazing of gold in antiquity has been adequately reviewed in this journal in 1973 (5). Summarized below are those aspects of the field which are of direct relevance to the analytical data reported 
in this article.

It is known from antiquity that there were two recipes in use for the preparation of gold solders (6); one derived from 'natural' chrysocolla (from the greek $\kappa \rho \nu \sigma o$ and $\kappa o \lambda \lambda \alpha$ or gold-solder), the other described the mixing of metals such as copper, silver and gold.

'Gold-solder is a liquid found in the shafts we spoke of, flowing down along a vein of gold, with a slime that is solidified by the cold of winter even to the hardness of pumicestone. A more highly spoken of variety of the same metal has been ascertained to be formed in copper mines, and the next best in silver mines. A less valuable sort also with an element of gold is also found in lead mines. In all these mines however, an artificial variety is produced that is much inferior to the natural kind referred to; the method is to introduce a gentle flow of water into the vein all winter and go on till the beginning of June and then to dry it off in June and July, clearly showing that gold-solder is nothing else than the putrefaction of a vein of metal. Natural gold-solder; known as 'grape', differs very greatly from the artificial in hardness, and nevertheless it also takes a dye from the plant called yellow-weed. It is of a substance that absorbs moisture, like flax or wool. It is pounded in a mortar and then passed through a fine sieve, and afterwards milled and then sifted again with a finer sieve, everything that does not pass through the sieve being again treated in the mortar and then milled again. The powder is all along separated off into bowls and steeped in vinegar so as to dissolve all hardness, and then is pounded again and then rinsed in shells and left to dry. Then it is dyed by means of 'spittable' alum and the plant above mentioned and so given a colour before it serves as a colour itself. It is important how absorbent it is and ready to take the dye; for if it does not at once catch the colour, scytanum and turbistum must be added as well - those being the names of two drugs producing absorption.'

The preparation of the two kinds of gold solders are also described in the Leyden Papyrus X: for artificial chrysocolla,

'Copper of Cyprus: 4 parts; assem: 2 parts; gold: 1 part; the copper is melted first, then the assem and finally the gold.'

and for the second, other, gold solder:

'Gold: 2 parts, copper: 1 part; melt and shake up. If you want a brilliant colour, melt with a little silver.'

This last procedure gives an excellent brazing alloy comparable with those used today. The nature of assem used in the second preparation has not yet been established. For the Egyptians the meaning of assem was essentially the same as electrum: natural alloy of gold and silver. It may be recognized as an alloy of silver, copper and tin (8), but it may be made also from other metals or even different minerals. The term assem has been also used to describe any substance the properties of which (colour, brightness, mass for instance) resemble those of precious metals(8).

Since the second half of the last century, brazing alloys containing cadmium have been extensively used. A small amount of cadmium in a gold matrix is capable of lowering the melting point of the brazing alloys to below that obtained by introducing equivalent concentrations of copper, and a fortiori zinc or silver in the same gold matrix. As reported more recently, the introduction of germanium in gold alloys gives rise to particularly interesting soldering alloys with low temperature melting point (9).

An extended and well documented discussion of different techniques of soldering in ancient jewellery has been published ten years ago by $A$. Thouvenin (10). In addition Thouvenin reproduced several pieces of jewellery workmanship ranging from Etruscan to Merovingian times. He concluded that goldsmiths of antiquity had skillfully achieved very fine and tiny solder joints, not by using brazing alloys (a technique useful only for 'macrosolders') but by diffusion at about $900^{\circ} \mathrm{C}$ of very fine powder of de-oxidized copper giving rise to, at 'microsites', in situ binary or ternary alloys: these would be binary when copper diffuses in pure gold or copper-gold alloys, ternary when it diffuses in gold-silver or copper-gold-silver alloys of high degree of fineness. Because that diffusion of copper takes place at temperatures higher than $890^{\circ} \mathrm{C}$, it would be essential to work with gold of a high degree of fineness in order to avoid, during the heating, fusion of the parts to be soldered. This procedure involved only local diffusion of copper-gold and avoided any bulging of material around delicate ornaments like granulations.

The work of Thouvenin on diffusion bonding completes and explains by chemical, physical and technical arguments the rediscovery of the soldering of granulations made by Littledale in I933 (11). For more details the reader should consult the recent paper in this journal and the book of $J$. Wolters on the subject (12).

\section{Cadmium and Forgery}

The presence of cadmium in a piece of jewellery is often interpreted as identifying that piece as being from modern origin: cadmium has indeed been known since only around 1815 as a new chemical element after its discovery at that time by Strohmeyer.

Cadmium has been sometimes observed at concentrations of up to several per cent, but more often at lower concentration, mainly at sites where soldering is necessary to join together elements in

Fig. 4 Yellow greenockite coating on a sample of zinc blende ( $\mathrm{ZnS})$

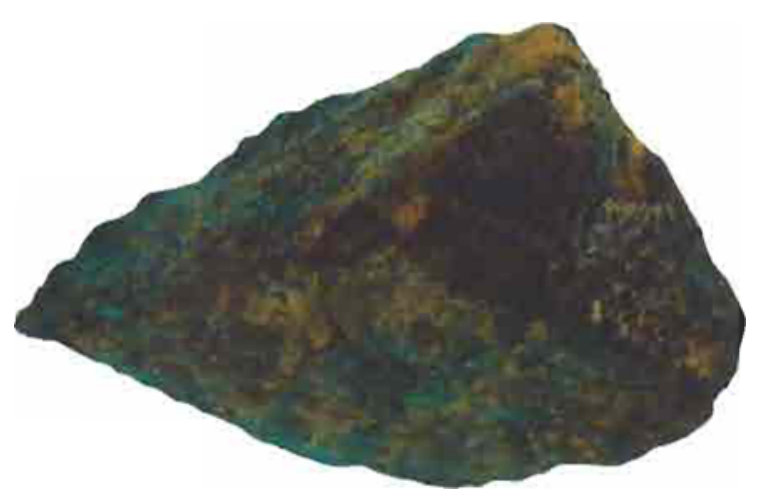


ostensibly ancient (but much debated) pieces of jewellery. We have demonstrated that the amount of cadmium found in such jewellery (originating often from Iran, Syria or Southern-Italy) was related to the amounts of copper and silver in proportions completely different from those observed in modern soldering alloys (4). For jewellery from ancient origin one observes a correlation in cadmium and copper contents: both chemical elements increase simultaneously at sites where some soldering is perceptible or expected. From observation of modern soldering alloys an inverse correlation of cadmium and copper contents is always observed, one reason being that for a given degree of fineness (say 750/1 000) of the soldering alloys the copper and/or silver contents decrease when the cadmium content is increased (13).

Fuller discussion of the parameters governing the differences between modern and ancient soldering has been given by the author and his colleagues elsewhere $(4,14)$.

Measurements on monetary medallions recently discovered (pieces of jewellery from the Houmeau site, La Rochelle, France) and analyzed in the Laboratoires des Musées de France (Louvre) and also at LARN indicate the presence of cadmium only at trace level (15). A tentative interpretation of the authors of this discovery, after discussion with geologists, postulates that the metal used for the medallions may have been extracted from zinc ores containing cadmium and gold (both as traces) as observed in mines of the region of Zarechouran (Iran).

We have also observed that antique jewellery made in one single piece and thus for which no soldering is necessary sometimes

\section{Table II}

Analytical Results for Different Areas on the Plate-Buckle of Pouan

\begin{tabular}{l|r|r|r|l}
\hline \multirow{2}{*}{ Impact No. } & \multicolumn{2}{|c|}{ Element concentration, \% } & \multirow{2}{*}{$\begin{array}{l}\text { Confidence } \\
\text { factor }\end{array}$} \\
\cline { 2 - 4 } & $\mathrm{Cu}$ & $\mathrm{Ag}$ & $\mathrm{Au}$ & \\
\hline P1 & 1.25 & 5.55 & 93.20 & 0.98 \\
P2 & 1.00 & 8.90 & 90.10 & 0.97 \\
P3 & 0.85 & 7.35 & 91.80 & 0.97 \\
P4 & 1.20 & 9.50 & 89.30 & 0.95 \\
P5 & 14.70 & 13.65 & 71.65 & 1.02 \\
P6 & 0.70 & 7.70 & 91.60 & 0.87 \\
P7 & 1.10 & 6.65 & 92.25 & 1.03 \\
P8 & 0.80 & 6.80 & 92.40 & 0.99 \\
P9 & 1.15 & 7.00 & 91.85 & 1.03 \\
P10 & 1.25 & 6.90 & 91.85 & 1.01 \\
P11 & 0.80 & 7.50 & 91.70 & 1.05 \\
P12 & 1.95 & 7.85 & 90.20 & 1.03 \\
P13 & 1.50 & 7.95 & 90.55 & 1.03 \\
& & & & \\
Mean Value & & & & \\
1-4 and 6-13 & 1.15 & 7.45 & 91.40 & \\
& & & &
\end{tabular}

contains cadmium at low concentration, and generally inhomogeneously distributed in the bulk of the material(16). This observation may be explained by assuming that the jewellery has been made with material obtained by melting an older gold jewellery piece containing cadmium as a soldering component. This cadmium content was then diluted and unevenly distributed in the metal when it was remelted. This last interpretation of cadmium content is also valid for the Houmeau jewellery.

Cadmium is a rare element in natural minerals, often present in traces in zinc and lead ores. Sometimes it appears as an orangeyellow coating (cadmium sulphide or greenockite) on zinc materials, and particularly on blende (Figure 4). The main locations of occurrence in Europe are Dumfries (Scotland), Pribram (Czechoslovakia) and Bleiberg (Carinthia, Austria). It is also found at Montevecchio (Sardegna, Italy) and Laurium (Greece) (17). As cadmium sulphide and zinc ores are different with regard to their crystallographic properties, crystals of greenockite may easily be isolated from their mineral backing of blende, merely by a gentle brushing. The powder such as that which we have collected by this means is a nearly pure cadmium sulphide. It is thought that it is not improbable that the colour of such natural crystals has intrigued jewellery craftsmen of antiquity when searching for materials, not only to be soldered, but also to be substituted for gold or gold alloys.

\section{Artifact Analysis - Results and Discussions}

More than 2000 narrow regions on at least 150 items of ostensibly ancient jewellery have been analyzed. These come from five museums and from five private collections. Due to the present controversy surrounding the existence of cadmium in ancient jewellery, understandably no details are given here of their location. During the analyses, special emphasis has been placed at sites on the pieces where some soldering is clearly 'visible' or expected by the construction of the artifact. From the composition of the surrounding neighbourhood, it is possible to interpret the procedure of brazing or soldering.

We will restrict our comments to three classes of solders observed on three characteristic artifacts.

Tables II to IV summarize the results of the analyses obtained by the milliprobe PIXE method.

Impacts $\mathrm{P} 1$ to P14 concern a plate-buckle assembly excavated in 1842 at Pouan (Aube, France) with 13 other objects including two swords with gold ornaments on their sheaths and among others pommels, bracelet, torques, ring. These objects are now in the Musée Archéologique de Troyes (France). They are attributed to the tomb of Theodoric, King of the Wisigoths killed in 451 during the battle of Champs Catalauniques $(18,19)$.

All the analytical data, except at impact P5, indicate that the material at solder sites as well as that in the bulk of the piece has nearly the same composition. No increase of copper is observed at solder joints. The different parts of the artifact seem to have been bound together by local heating without any addition of fusible 
Table III

Analytical Results for Different Areas of the Askos Earring

\begin{tabular}{|c|c|c|c|c|}
\hline \multirow[t]{2}{*}{ Impact No. } & \multicolumn{3}{|c|}{ Element concentration, $\%$} & \multirow{2}{*}{$\begin{array}{l}\text { Confidence } \\
\text { factor }\end{array}$} \\
\hline & $\mathrm{Cu}$ & $\mathrm{Ag}$ & $\mathrm{Au}$ & \\
\hline T1 & 1.85 & 3.75 & 94,40 & 1.03 \\
\hline T2 & 8.75 & 4.25 & 87.00 & 1.02 \\
\hline T3 & 0.90 & 4.35 & 94.75 & 1.05 \\
\hline T4 & 2.85 & 3.20 & 93.95 & 1.00 \\
\hline T5 & 1.20 & 4.20 & 94.60 & 1.07 \\
\hline T6 & 1.20 & 3.95 & 94.85 & 1.02 \\
\hline T7 & 1.10 & 3.60 & 95.30 & 1.03 \\
\hline T8 & 1.35 & 3.80 & 94.85 & 1.03 \\
\hline $\mathrm{T} 9$ & 2.10 & 6.45 & 91.45 & 0.97 \\
\hline T10 & 2.15 & 6.05 & 91.80 & 1.02 \\
\hline T11 & 1.55 & 6.65 & 91.80 & 0.94 \\
\hline
\end{tabular}

$T 6, T 7, T 8$ separate granule (side applied on the body); $T 9, T 10, T 11$, this separate granule (outside)

Table IV

Analytical Results for Different Areas of the Byzantine Phial

\begin{tabular}{|c|c|c|c|c|c|c|}
\hline \multirow{2}{*}{$\begin{array}{l}\text { Impact } \\
\text { No. }\end{array}$} & \multicolumn{4}{|c|}{ Element concentration, \% } & \multirow{2}{*}{$\begin{array}{l}\text { Con- } \\
\text { fidence } \\
\text { factor }\end{array}$} & \multirow[t]{2}{*}{ Remarks } \\
\hline & $\mathrm{Cu}$ & Ag & Cd & $A u$ & & \\
\hline PH1 & 0.65 & 0.45 & 0.40 & 98.50 & 0.98 & \\
\hline $\mathrm{PH} 2$ & 0.25 & 0.35 & 0.10 & 99.30 & 0.94 & \\
\hline PH3 & 2.60 & 1.35 & 0.40 & 95.65 & 1.00 & \\
\hline $\mathrm{PH} 4$ & 2.10 & 1.60 & 0.10 & 96.20 & 1.01 & \\
\hline PH5 & 4.05 & 1.35 & 1.85 & 92.75 & 1.00 & \\
\hline PH6 & 8.35 & 0.25 & 6.25 & 85.15 & 1.07 & \\
\hline PH7 & 2.40 & 1.40 & 0.45 & 95.75 & 1.07 & \\
\hline PH8 & 3.25 & 0.95 & 2.00 & 93.80 & 0.92 & Reverse* \\
\hline PH9 & 1.05 & 0.45 & - & 98.50 & 1.02 & \\
\hline $\mathrm{PH} 10$ & 2.55 & 0.95 & 1.05 & 95.45 & 0.98 & \\
\hline PH11 & 2.35 & 1.05 & 0.85 & 95.75 & - & \\
\hline PH12 & 0.25 & 0.40 & - & 99.35 & 0.96 & Reverse* \\
\hline PH13 & 2.05 & 1.45 & 0.30 & 96.20 & 0.95 & Reverse* \\
\hline PH14 & 0.20 & 0.50 & 0.10 & 99.20 & 0.95 & \\
\hline PH15 & 1.15 & 1.60 & 0.10 & 98.15 & - & \\
\hline PH16 & 0.45 & 0.35 & 0.20 & 99.00 & 1.03 & \\
\hline PH17 & - & 0.45 & - & 99.55 & 0.98 & \\
\hline $\mathrm{PH} 18$ & 0.20 & 0.40 & - & 99.40 & 0.98 & Reverse* \\
\hline PH19 & 0.35 & 0.50 & 0.25 & 98.90 & 1.00 & \\
\hline $\mathrm{PH} 20$ & 2.00 & 1.70 & 0.15 & 96.15 & 0.98 & \\
\hline PH21 & 0.05 & 0.40 & - & 99.55 & - & \\
\hline PH22 & 1.15 & 1.25 & - & 97.60 & 1.06 & \\
\hline PH23 & 0.95 & 1.00 & - & 98.05 & 1.00 & Inside \\
\hline PH24 & 0.75 & 0.75 & 0.20 & 98.30 & 1.07 & \\
\hline PH25 & 2.80 & 1.05 & 2.25 & 93.90 & 1.02 & \\
\hline PH26 & 1.30 & 1.00 & - & 197.70 & 0.97 & \\
\hline
\end{tabular}

alloy. Bonding by local diffusion of copper powder may not be expected here: diffusion bonding is of no use when the joints are so large and the soldering of the inner components to the external body is not meticulously carried out (Figure 5).

The solders are actually shaped by the interior and have to be hidden by the setting of the stones (garnets). The object was designed to be more utilitarian than decorative. Nevertheless the quality of the material indicates that it was worn by a prince or a king. The tongue (P11) is of the same composition as the rest of the object. While seven garnets are missing on this plate-buckle, a second piece of the same workmanship is still complete, the three rivets for the fastening on the belt being included. The total length of the artifact is $4.6 \mathrm{~cm}$. The differences visually and in the composition at impact P5 indicate that the ring housing the articulation of the buckle is of modern origin.

In Tables II to $V$ the accuracy of all the analytical data resulting from the various impact points has been given by confidence factors (which take into account the ratio of intensities of gold $\mathrm{L} \alpha$ and $\mathrm{L} \beta$ lines), the method of calculation of which is described in detail elsewhere $(3,16)$. A confidence factor of between 0.97 and 1.03

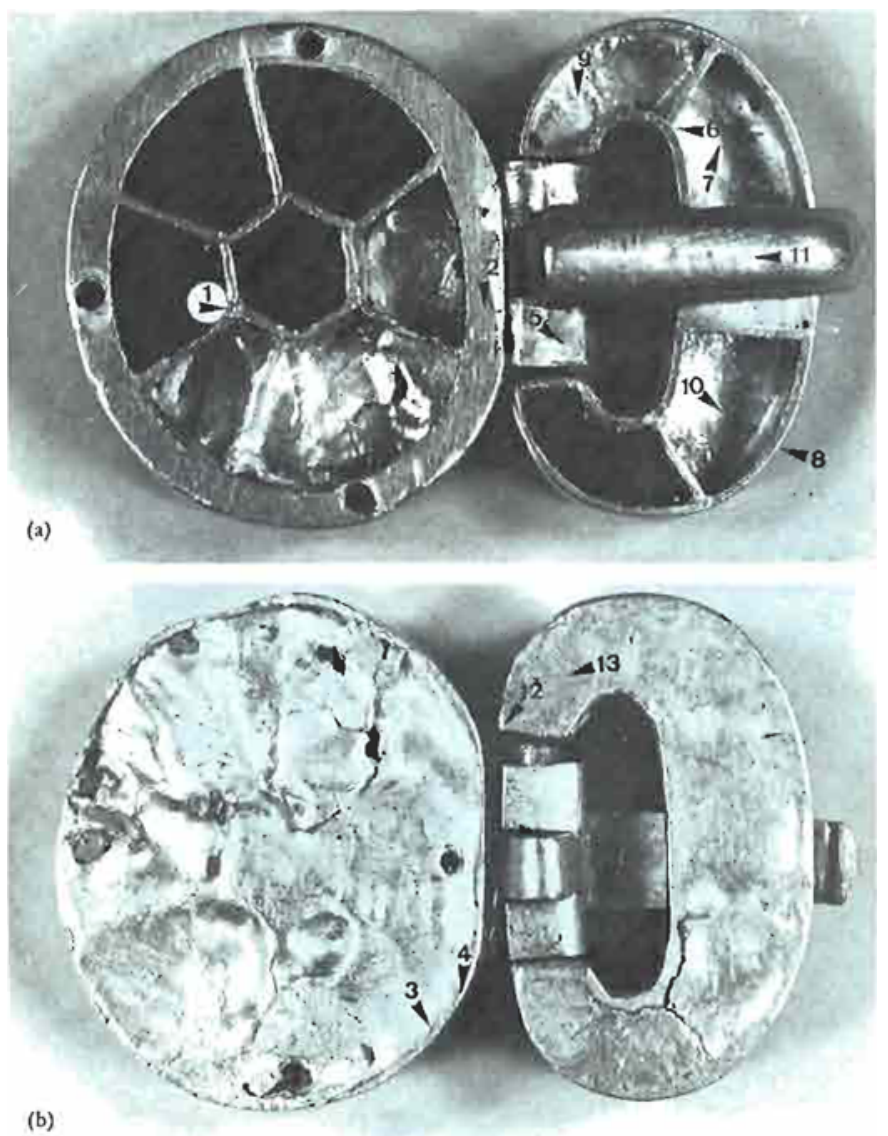

Fig. 5(a) The plate-buckle of Pouan with the corresponding impacts (see Table II) (b) The reverse side of the plate-buckle shown in (a) 
indicates a meaningful analytical result. Confidence factors of less than 0.97 indicate that shadowing of the emerging $\mathrm{X}$-rays may be suspected, thus a confidence factor far below unity implies that the measured concentration of copper (which produces characteristic $\mathrm{X}$-rays of lower energy) may be an underestimation. This is the case for $\mathrm{P} 6$, an impact in a deep hollow in a solder region. Conversely a confidence factor far above unity indicates that the $\mathrm{L} \alpha$ line is superimposed with one other line and that a significant amount of zinc may be present. As each element gives more than one

Fig. 6 Impact sites of proton bombardment during PLXE analysis of the Askos pair of earrings

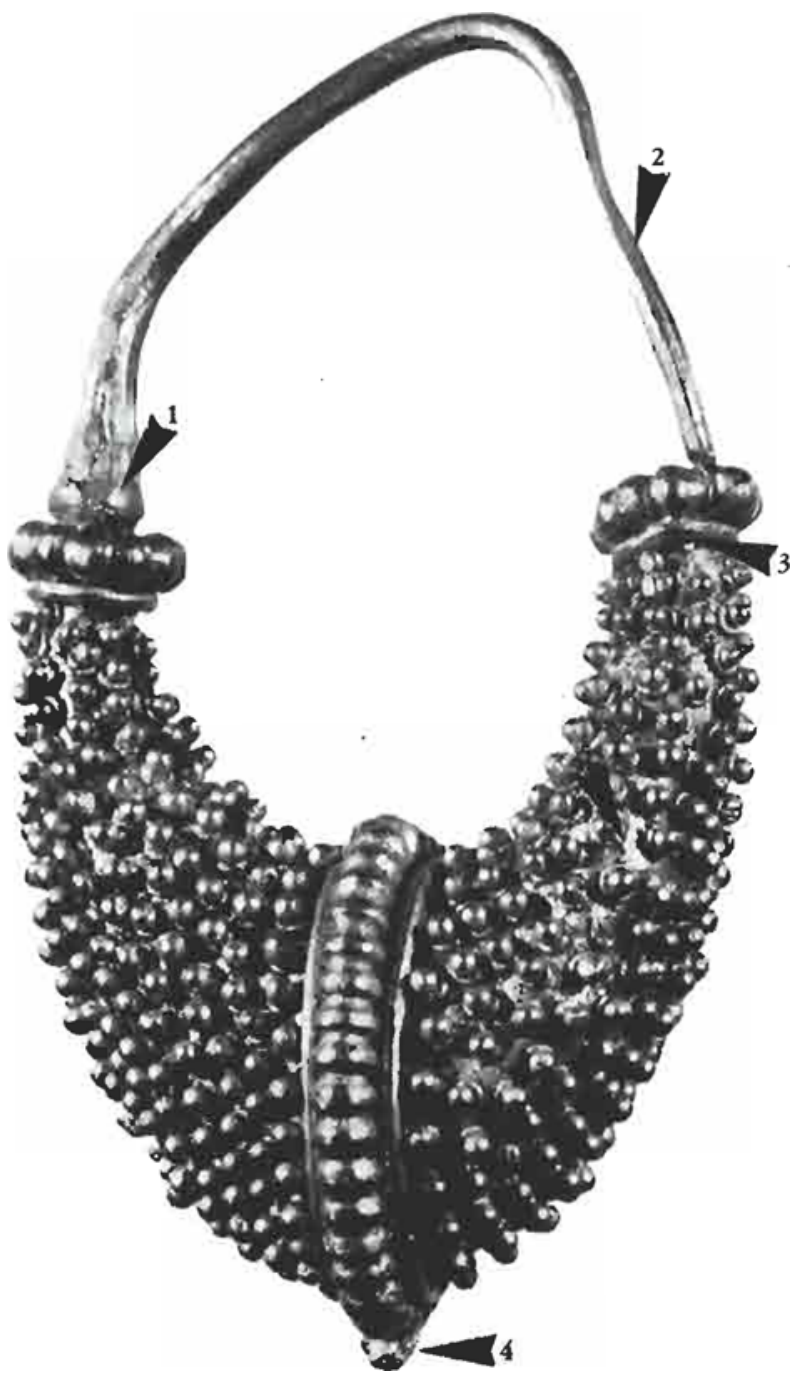

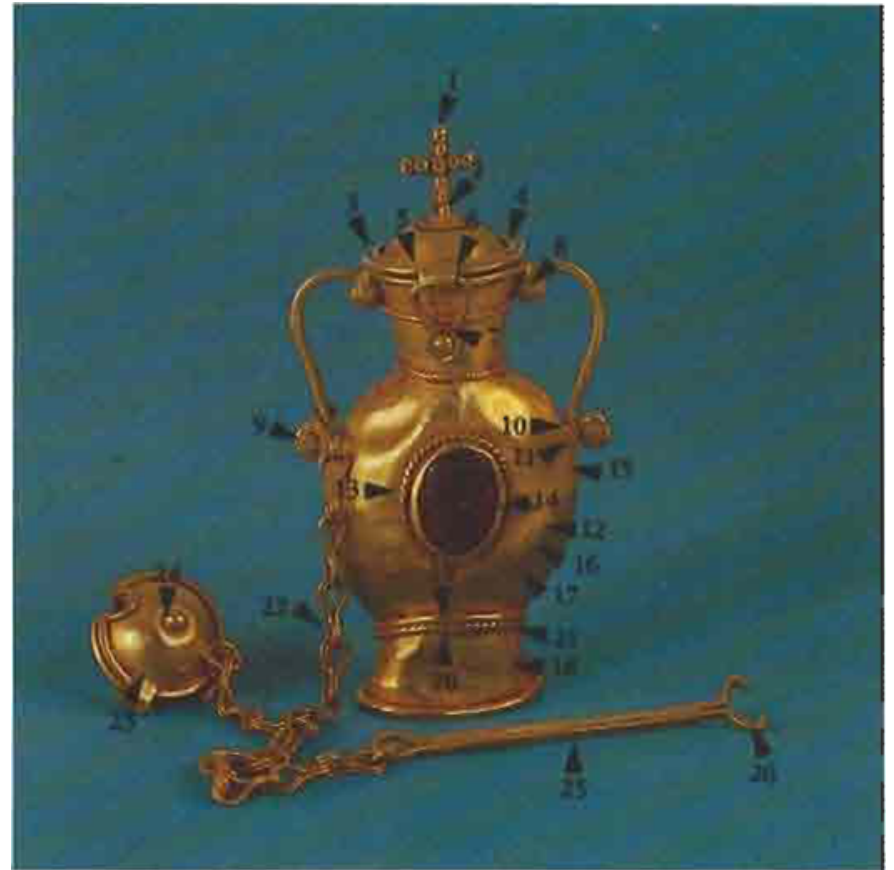

Fig. 7 The Byzantine phial used as a container for Christian holy oils

characteristic X-ray line, the complete analysis of the full X-ray spectrum obtained by PIXE allows us to identify easily any systematic errors in the experimental procedure (3).

Results at impacts T1 to T11 have been obtained on one element of a pair of earrings of the askos type (see Figure 6) belonging to a family well known in the Tarento region of Southern Italy, and dating from the 4th century B.C. Each earring is a composition of two crescent-shaped gold leaves soldered together to give a hollow body which is covered by individual granules of regular shape and size $(0.7 \mathrm{~mm})$. A beaded wire surrounds vertically the maximum diameter of the hollow body. The maximum sizes of the two pieces are respectively 3.7 and $3.9 \mathrm{~cm}$, their masses 8.77 and $9.30 \mathrm{~g}$. The loop is a forged wire bulged at the soldered end. Regions where no solder is expected (T3, T5, T6, T7, T8) contain 1.15 per cent of copper and 4.00 per cent of silver, the balance being gold. The alloy of the loop (T2) contains more copper, and that of the beaded wire more copper and less silver. Results of measurements on a separate granule (T6, T7 and T8 for the side attached to the main body, T9, T10 and T11 for the outside surface) indicate that a material containing more copper and more silver has been used as the brazing alloy, probably supplied from the outside.

Most of the measurements performed at impacts F1 to F26 (Table IV) on a small phial (Figure 7) indicate the presence of cadmium at concentrations of up to several per cent in solder regions. This elegant little vessel with its egg-shaped belly decorated with two amethysts was found in the North of Syria. The byzantine crosses 
engraved on the amethysts imply that it was fabricated around the 10 th century A.D. The shell-shaped receptacle and the clip indicate that the vessel was designed to hold Christian holy oils. The artifact was loaned for analysis by a private foundation in Switzerland.

By visual inspection the joins of both handles on the neck and on the lateral surface of the vessel are likely to have been made with a brazing alloy. The other solders used to fix several ornaments (wires, filigrees and gold granulations) on the main vessel, to fix the hinges of the lid and of the shell-shaped receptacle, and to connect the two parts of the clip have been also analyzed. It is observed that the basic gold (F9, F12, F17, F18, F21, F23) is of very high fineness, more than $985 / 1000$ of gold. The alloys of the chain and of the clip contain more copper and more silver (F22, F26). At all impacts where cadmium is detected, it is apparent that the copper and the cadmium contents increase simultaneously. This correlation has been also observed on other objects discussed elsewhere $(4,20,21)$.

When the total amount of copper, silver and cadmium at each impact is normalized to 100 per cent, the 18 regions where cadmium is detected give rise to 18 representative points reproduced in the ternary diagram of Figure 8 , revealing clearly the correlation between cadmium and copper.

Conversely when the same calculation is made for modern soldering alloys, taken as purchased, melted in a refractory crucible or used for the brazing of gold pieces, the representative points lie on a line the slope of which is completely different (Figure 9): inverse correlation of copper and cadmium contents is now observed.

We have interpreted the differences between ancient and modern cadmium-containing solders by postulating that in these two types of soldering alloys cadmium undergoes different types of chemical bonding $(4,14)$. This interpretation takes into account the fact that optical luminescence is of ten observed during the proton irradiation of old artifacts, but not when modern solders are irradiated by the same conditions.

Having advanced new hypotheses to explain these differences between modern and apparently old cadmium-containing solders, we have also tried to reproduce, in the laboratory, soldering alloys by methods known to ancient metal workers $(6,7)$, for example by 'alloying' not the metals but their minerals (21).

\section{Reproducing Ancient Solders}

By very rudimentary means, heating gold of different degrees of fineness with cadmium sulphide in a carbon crucible, solder alloys which work well have been obtained.

A few milligrams of gold were heated at a temperature sufficient to melt the gold and to form a little sphere in the bottom of the crucible. Cadmium sulphide powder was then sprinkled into the melted gold and was seen to be instantaneously dissolved. The small alloy sphere was then microscopically analyzed.

Each alloy sample appears to be quite homogeneous. The centres of the alloy spheres often contain less cadmium than the surface but the difference in these concentrations is always less than 20 per cent.

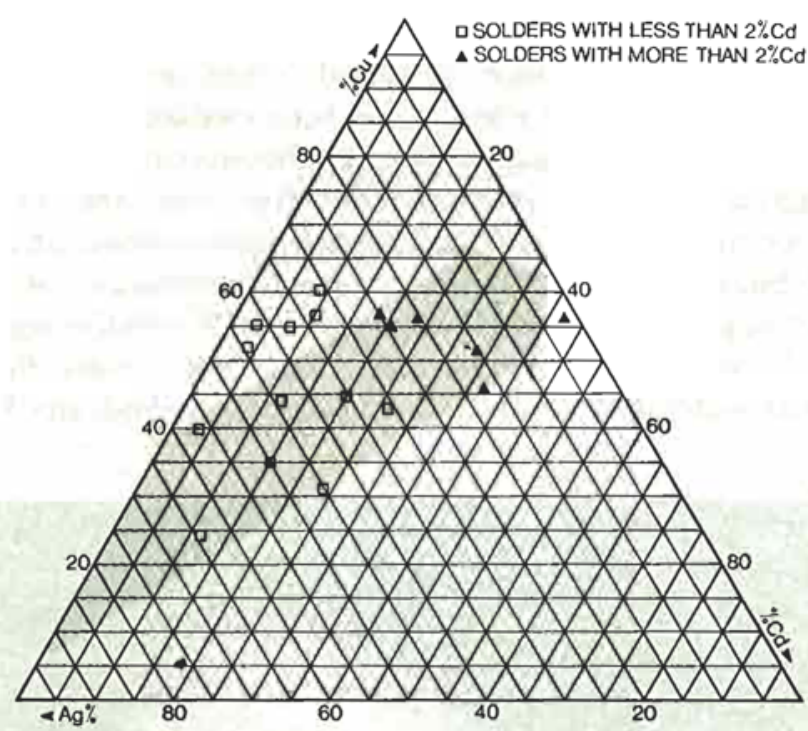

Fig. 8 Ternary compositional diagram showing the correlation of copper and cadmium concentrations in solder areas on the Byzantine phial

Fig.9 Ternary compositional diagram showing the inverse correlation of copper and cadmium concentrations in modern soldering alloys

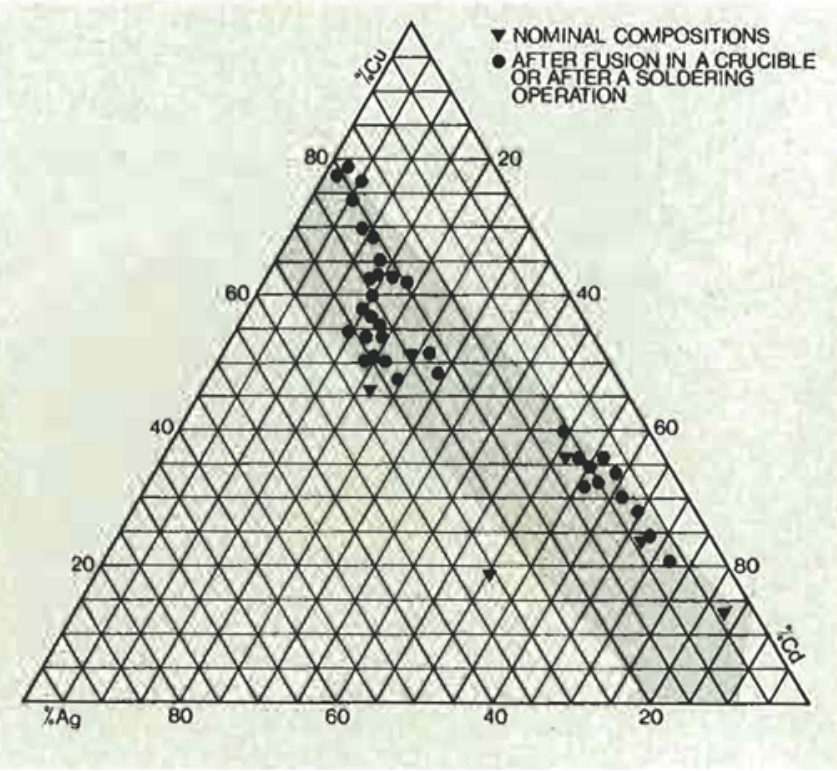


Although other factors such as shape of crucible, the addition of copper and iron minerals, how far above the gold melting temperature the mixture is heated, which are still being investigated, have an effect, it has been established that the solubility of the cadmium sulphide reaches saturation when the cadmium content lies between 1 and 10 per cent. Addition of copper minerals to the cadmium sulphide enhances the cadmium solubility. Thermal analysis of such mixtures indicates that the melting point of the alloy may be lowered to $720^{\circ} \mathrm{C}$ even if its degree of fineness is greater than 850/1 000. Spark source mass spectrometry, used for the analysis of trace elements, indicates that
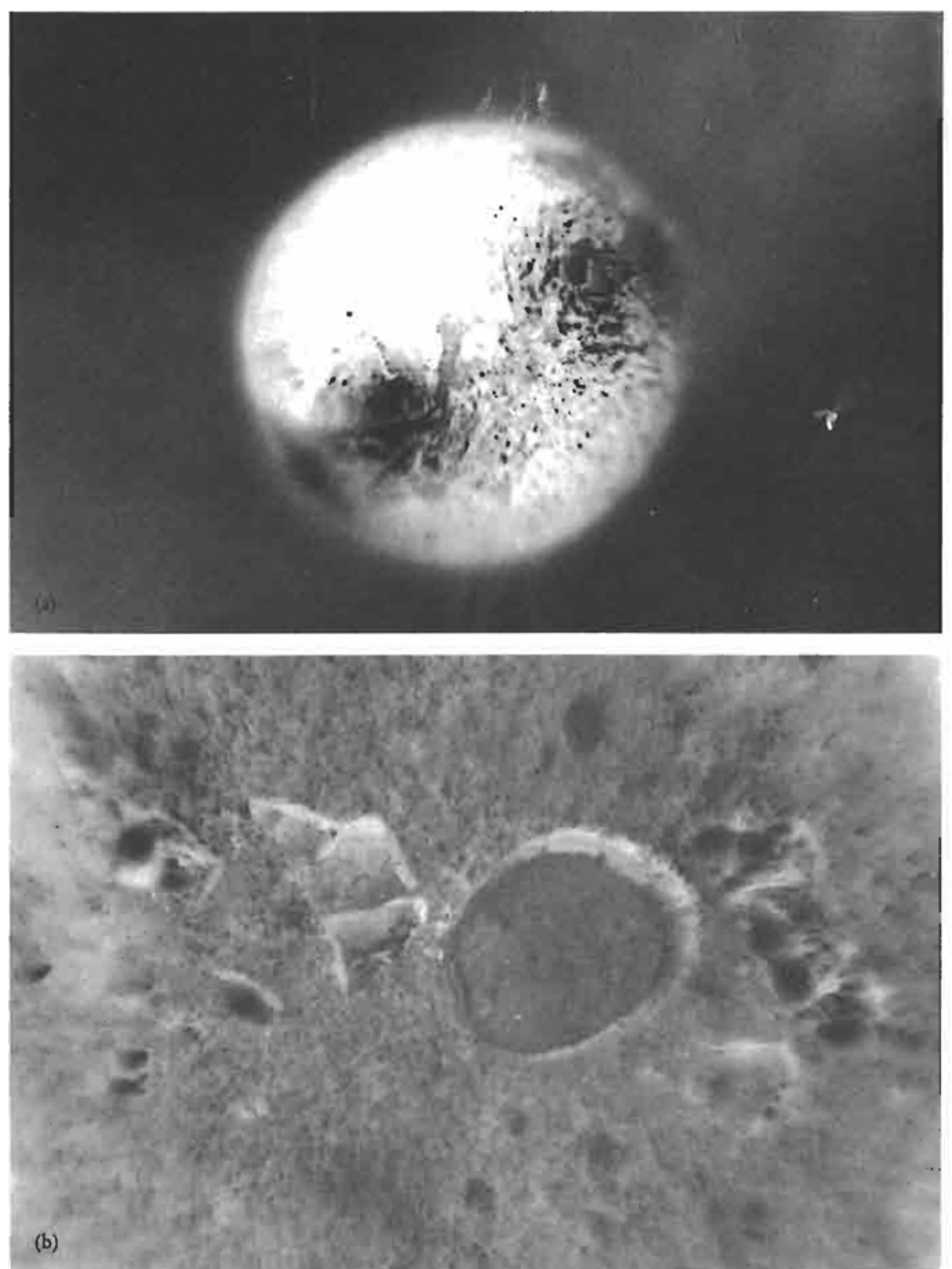

at least 95 per cent and sometimes all of the sulphur (introduced with the cadmium sulphide) is eliminated during the alloying procedure.

The soldering alloys obtained by dissolution of cadmium sulphide in a gold matrix up to saturation (indicated by the presence of yellow 'strings' floating over the melt surface in the crucible when additional cadmium sulphide is poured in the liquid gold) show a bigger endothermic peak than commercial soldering alloys, when studied by differential thermal analysis under nitrogen atmosphere.

The compositions of these soldering alloys remains constant during the short time of heating necessary for brazing.

When cadmium sulphide powder is mixed into turnings of gold and then heated to melting, dissolution takes a longer time than when greenockite is sprinkled in liquid gold. Furthermore, the alloy obtained by this procedure is less homogeneous. The sphere of goldcadmium alloy appears sometimes as in Figure 10a; gold-rich alloy at the top of the crucible with a black deposit appearing at the bottom. When such a sphere is gently compressed the black coating is easily separated (Figure 10b). When irradiated by the proton beam this black coating gives rise to optical luminosity similar to that reported above. The measured elemental concentrations are given in Table $V$ and correlation between copper and cadmium contents is observed. This correlation is observed in both the data on the black deposit where the gold content is less than 5 per cent and in the gold-rich alloy obtained simultaneously. This behaviour begs the question of whether cadmium sulphide cannot be used to purify gold! The corresponding ternary diagram of copper-cadmiumsilver (Figure 11) is very similar to that observed for artifacts like the phial.

Fig. 10 Small sphere of 'ancient' cadmiumcontaining soldering alloy made by reproducing methods used by metal workers in antiquity:

(a) after melting

(b) after gentle compression.

The black deposit around the cadmium gold alloy should be noted 


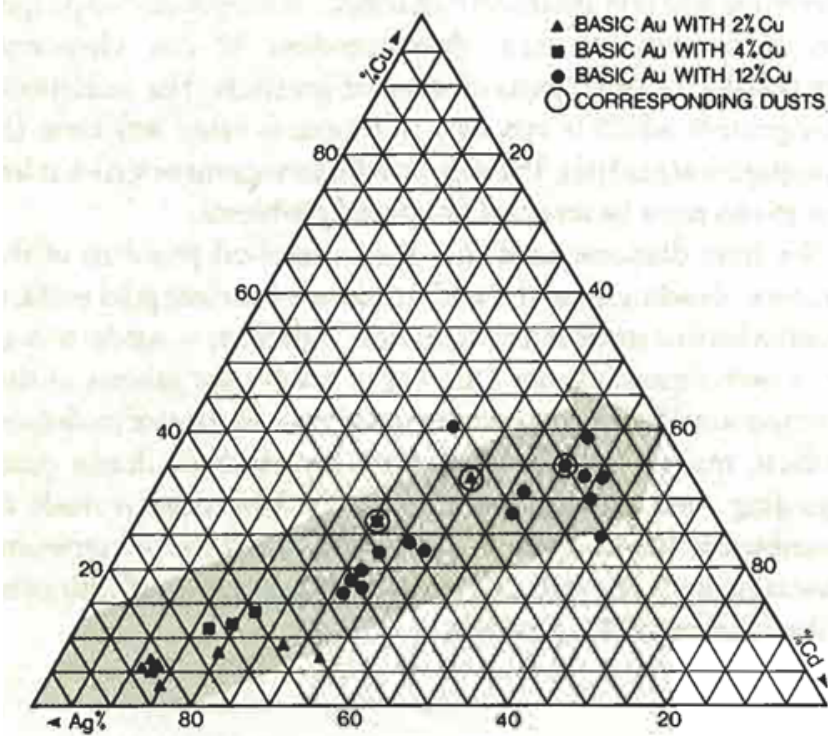

Fig. 11 Ternary compositional diagram of reproduced 'ancient' soldering alloys showing good correlation of cadmium and copper concentrations
Table V

Analytical Results from Different Areas of a Gold Solder Prepared by 'Ancient' Techniques

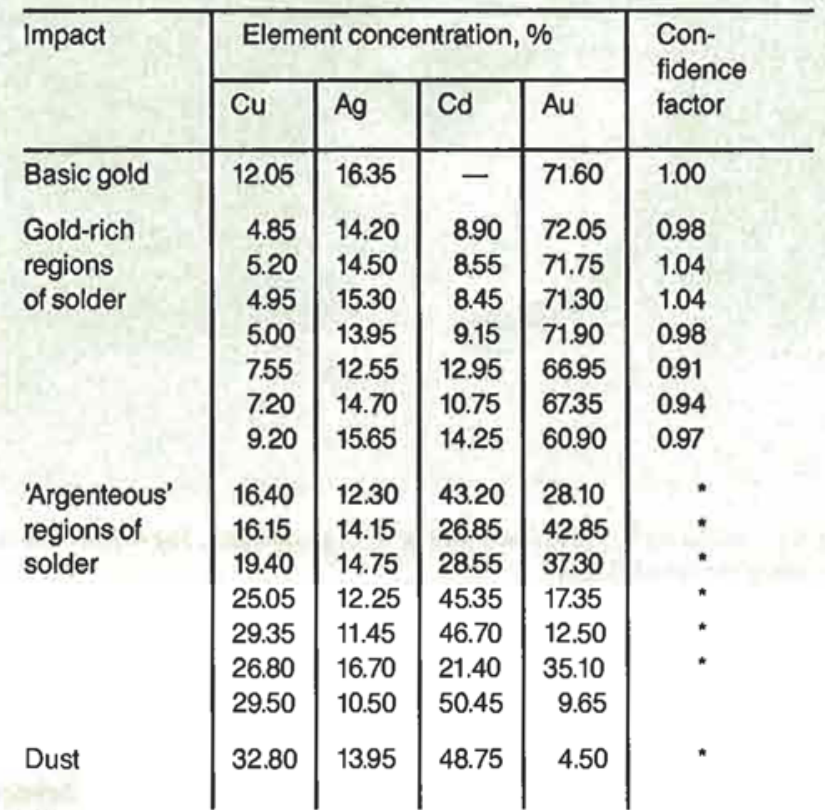

-The amount of gold is too low to consider the L $\alpha / L \beta$ ratio to be sufficiently significant for the calculation of a confidence factor
Figure 12 illustrates the procedure for the soldering of a granule $(2 \mathrm{~mm}$ in diameter) on a thin sheet of pure gold using an interposed turning of the reproduced 'ancient' soldering alloy. Figure 13 shows a small granule of 0.5 $\mathrm{mm}$ in diameter soldered onto its gold base without the use of normal brazing alloys but by simply heating the gold sheet coated with a small amount of cadmium sulphide at the site of the granule. This type of soldering may be readily compared to diffusion bonding, avoiding any bulging in the neighbourhood of the tiny granule and being very suitable for soldering of granulations.
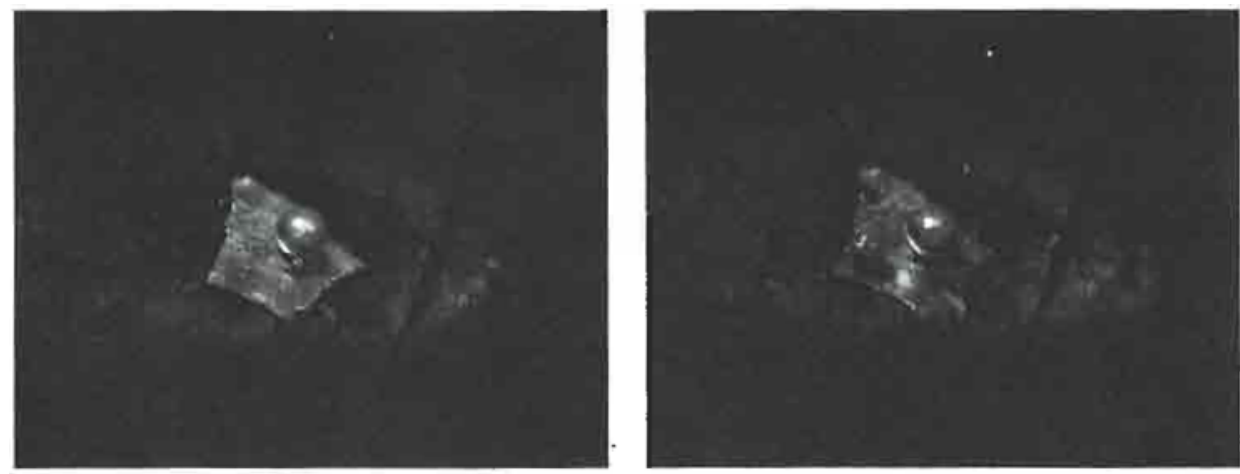

Fig. 12 Gold sheet with a small türning of reproduced 'ancient' solder supporting a small sphere of gold $2 \mathrm{~mm}$ in diameter:

(a) before heating

(b) after heating on charcoal using a blow-pipe, and after joining

(c) view of the solder region af ter a first heating with the blow-pipe acting from the left side

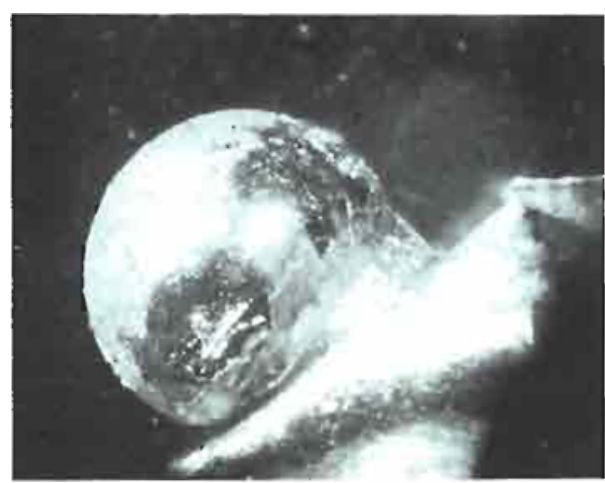




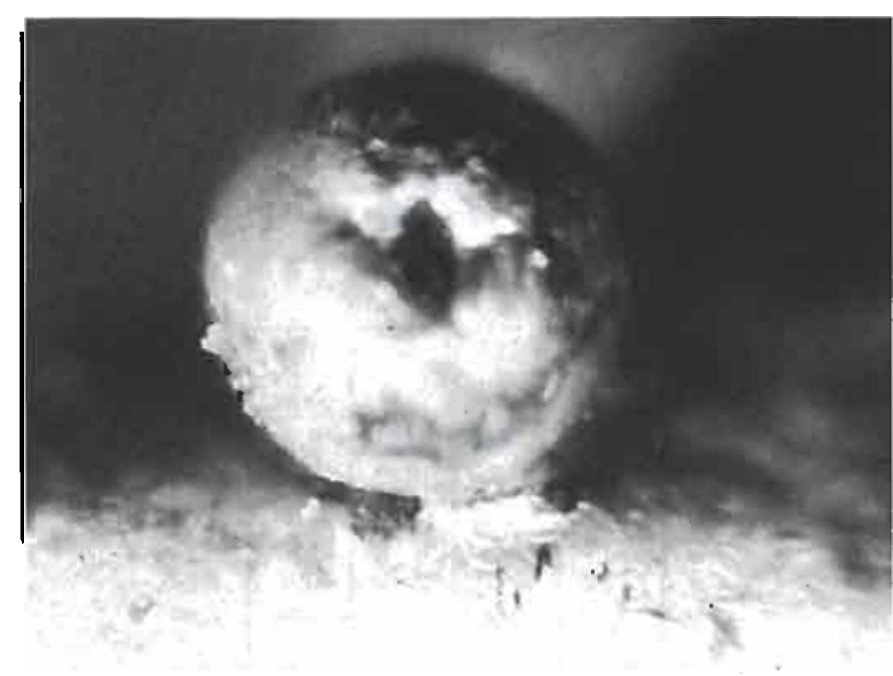

Fig. 13 Soldering by 'diffusion bonding' with greenockite. The diameter of the granule is less than $0.5 \mathrm{~mm}$

\section{Conclusions}

PIXE, with its complementary technique PIGE, is a very interesting and non-destructive analytical technique allowing rapid and sufficiently accurate determination of the elemental composition of small parts of items of jewellery. The milliprobe arrangement which is very easy to process is often sufficient for topographical analysis. The microprobe arrangement which is less easy to run must be reserved for special problems.

We have demonstrated that the unresolved problem of the presence of cadmium in the soldered areas of ancient gold artifacts requires further study but the criterion 'cadmium = modern' may be an over-simplification. One way to resolve the validity of this criterion would be to carry out a careful examination of solders on artifacts, mainly from Iran and Syria, for which no doubt exists regarding their authenticity. The LARN laboratory is ready to contribute to this task, and it is hoped that a number of museums possessing both material and advanced equipment will also assist in the solution of this problem.

\section{Acknowledgements}

Mr. Sainte Marie, Curator of the Museum of Troyes (France) is acknowledged for giving his permission to analyze several objects from his museum and to reproduce some of the results.

Numerous people have contributed to the progress of the reported research. Wo thank Prof. T. Hackens (Universiry of Louvain) who introduced the author to the study of gold jewellery, Prof. G. Nicolini (University of Poitiers) and Dr. P. Meyers(County Museum of Arts, Los Angeles) for their valuable advice and suggestions (including those conrradictory to the author's theories), Dr. B. Van Oystaeyen, Mr. Y. Morciaux and Miss A. Boullar, for their assistance in running the experiments including irradiation, calculation, and interpretation, those collectors (private and museums) from whom the artifacts were borrowed, Dr. Mauterer(Vienna) and Dr.Z. Gabelica (Namur) for their suggestions relating to physico-chemical problems, Prof. P. Overlau (Namur) and Mr. G. Coussement (Bruxelles) for their collaboration on geological aspects.

\section{References}

1 G. Deconninck, G. Demortier and F. Bodart, At. Energy Rev, Suppl. No. 2, 198I, pp. 151.234

2 J.L. Debrun, Anal. Chem., 1976, 48, 167

3 B. Van Oystaeyen and G. Demortier, Nucl. Instr. Meth., 1983, 215, 299-313

4 G. Demortier and T. Hackens, Nucl. Instr. Meth., 1982, 197, 223-236

5 P.M. Roberts, Gold Bull., 1973, 6, 112-119

6 L.B. Hunt, Gold Bull., 1976, 9, 24-3

7 H. Rackham, 'Pliny. Natural History', Vol. 9, Loeb edition, Book 33, Chapter 26, Heinemann, London and Harvard Universiry Press, 1968. See also K.C. Bailey 'The Elder Pliny's Chapter on Chemical Subjects' Vol. 1. E. Arnold, London, 1929

8 M. Berthelot, 'Introduction à l'Ezude de la Chimie des Anciens et du Moyen Âge', Editions Georges Steinheil, Paris, 1889

9 G. Zwingmann, Gold Bull., 1978, 11, 9-14

10 A. Thouvenin, 'La Soudure dans la Construction des Oeuvres d'Orfévrerie Antique at Ancienne', Revue Archéologique de l'Est et du Centre-Est, France, $1973,24,11.68$

11 H.A.P. Littledale, U.K. Pat. 415181 (1936)

12 J. Wolters, Gold Bull., 1981, 14, 119-129 and 'Granulation - Geschichte und Technik einer alten Goldschmiedekunst', Verlag Callway (München), 1983

13 G. Demortier, in 'A new $A$ pproach to Ancient Gold Brazing', 2nd Internat. Symp. on 'Historische Technologie der Edelmetalle', Meersburg, Germany, 1983 (notes for participants - unpublished)

14 G. Demortier and F. Bodart, J. Radioanal. Chem., 1981, 69, 239-257

$15 \mathrm{~J}$. Flouret, G. Nicolini and C. Metzger, 'Les Bijoux d'Or Gallo-Romains de l'Houmeau (Charente-Maritime)', Gallia - Foullles et Monuments Archéologiques en France Métrobolitaine, 1981, 39, 85-101

16 G. Demortier, "Topographical Non-Destructive Analysis of Gold Jewellery' in 'Gold Jewellery-Craft, Style and Meaning from Mycenae to Constantinopolis', Aurifex 5, edited by 'T. Hackens and R. Winkes, Institut d'Archéologie et d'Histoire de l'Art, Louvain-la-Neuve, Belgium, pp. 215-227, 1983

17 E.S. Dana and W. Ford, 'A Textbook of Mineralogy Crystallography and Physical Mineralogy', J. Wiley (New York)

18 Childeric-Clovis, '1500' Anniversaire (482-1982)'. Catalogue de l'exposition, Casterman (Tournai), 1982, (one bound volume of 240 pages)

19 J. Bienaimé, 'Le Trésor de Pouan', Les cahiers des Musées de Troyes, No. 1, (15 pp.)

20 G. Demortier, in 'LAnalyse Élémentire Non Destructive d'Objects d'Orfevrerie par Irradiation au moyen de Particules Chargées et Détection Simultaneée des Informations. 1. Relations fundamentales. 2. Analyse de quelques colliers', Aurifex 4. (Institut d' Archaéologie et d'Histoire de l'Art, Louvain-la-Neuve, Belgium, (in press)

21 G. Demortier, in 'Le Cadmium a-t-il été Utilisé en Bijouterie Antique?', Archéologia (Prébistoire et Archéologie), Dijon (France), 1983, 176, 41-50 